\title{
SISTEMAS PARALELOS DE PROMOÇÃO E DISTRIBUIÇÃO
}

\section{LEO ASPINWALL}

Há uma relação intima entre a melhor forma de distribuir um produto e a de mais eficientemente promovê-lo. Baseando-se nas principais características mercadóógicas dos bens, o autor desenvolveu uma teoria que coordena os dois aspectos, de molde a torná-los diretamente aplicáveis a qualquer produto.

o fabricante de um produto precisa decidir de que forma irá promovê-lo e que vias usará para sua distribuição. Uma grande variedade de possibilidades se lhe apresenta, neste particular, tanto para estimular a procura, como para levar o produto ao consumidor. Existe um paralelismo entre êstes dois aspectos do problema mercadológico, ocorrendo comumente juntos os sistemas de distribuição e promoção, devido a que ambos dependem das características mercadológicas do produto.

Demonstraremos, a seguir, de que forma podem os bens ser classificados, arranjados numa escala numérica e representados gràficamente. Indicaremos, também, de que maneira a posição de um produto, nessa escala, pode ser utilizada para identificar os sistemas paralelos de promoção e distribuição que devem ser usados na sua mercadização. Assim, a uma

LEO ASPINWALL - Professor Emérito da «School of Business» da «University of Colorado».

NOTA: Este artigo, reproduzido sob autorização, é uma tradução condensada de "The Characteristics of Goods and Parallel Systems Theories», publicado em «Managerial Marketing, Perspectives and Viewpoints», de Eugene J. Kelley e William Lazer, Richard D. Irwin, Inc., Homewood, Illinois, 1958. 
breve análise da classificação dos produtos faremos seguir uma explanação dos sistemas paralelos de promoção e distribuição.

\section{As Características Mercadológicas dos Bens}

A teoria das características dos bens tenta classificar, de forma sistemática, todos os bens negociáveis. Esta teoria já foi aplicada, com proveito, a situações reais e fornece uma perspectiva e um quadro de referência para a organização de fatos mercadológicos e a avaliação das decisões relativas à mercadização de produtos. Estabelece uma escala contínua de bens e define os critérios por que, a qualquer produto, se pode atribuir um determinado lugar dentro da mesma. Estes critérios apresentam a vantagem de, pelo menos potencialmente, prestarem-se a uma avaliação objetiva.

As características mercadológicas de um produto determinam o método mais apropriado e econômico de distribuí-lo. Estabelecer sua posição numa escala que represente a variação nessas características é dar o primeiro passo para entender seus requisitos mercadológicos. Conhecer essas características é adquirir a capacidade de prever, com grande segurança, de que forma um produto será distribuído, uma vez que a maior parte dos bens adere a um padrão. Assim, ao verificar-se um desvio acentuado do teòricamente esperado, haverá, quase certamente, necessidade de mudança e melhoria dos métodos usados para a distribuição.

Estas considerações se aplicam tanto à distribuição física quanto ao problema correlato de escolher os apelos e meios de promoção do produto. Segue-se, também, que os bens de características semelhantes exigem tratamento semelhante. E, por último, quando fôr possível atribuir pesos ou valores precisos a cada característica, sua combinação determinará a posição específica do produto na escala mercadológica.

A distribuição de bens se assemelha à de uma corrente elétrica através de fatôres de resistência, cada um absorvendo parte da margem bruta. Quando o produto finalmente chega às mãos do consumidor, pronto para ser usado, tôda a margem 
bruta já foi absorvida. Do ponto de vista do consumidor, a margem bruta de que abriu mão a fim de poder usufruir dos benefícios que o bem lhe ofereceria é, de fato, a voltagem que a corrente elétrica deve ter para que possa passar pelos fatôres de resistência e finalmente chegar ao consumidor.

Através do estabelecimento de critérios ou testes a que deveriam ser submetidas as diversas características, chegou-se a uma decisão relativa ao número e espécies de características a serem usadas. São os seguintes os critérios aventados :

1. Cada característica selecionada deve ser aplicável a todos os bens.

2. Cada característica selecionada deve ser mensurável em têrmos de sua relação com todos os bens.

3. Cada característica deve estar lògicamente relacionada a tôdas as outras características.

\section{Classificação das Características}

Aqui deveríamos definir o têrmo "característica". Característica é a qualidade que distingue um produto quanto ao seu desempenho num determinado mercado e à sua relação com os consumidores cujas necessidades satisfaz. De acôrdo com esta definição, foram selecionadas cinco características, que abaixo enumeraremos :

A. Freqüência de Substituição : - é a freqüência com que um bem é comprado e consumido. Está ligada ao fluxo ou movimento de unidades de um bem, desde o produtor até o consumidor final. Assemelha-se ao conceito de rotação de estoques, com a diferença que entendemos essa rotação como relacionada ao número de vêzes por anè que um estoque médio de mercadorias é comprado e vendido. O conceito de freqüência de substituição que aqui utilizamos é orientado para o consumidor, indagando com que frequiência o consumidor compra, por exemplo, sapatos - uma vez por mês, uma vez cada seis meses, uma vez por ano? Não se preocupa em saber se os sapatos foram realmente consumidos, mas sòmente com que frequiência o mercado deve estar pronto 
para colocá-los à disposição dos consumidores. Esta característica se refere ao processo de mercadização que é pôsto em movimento pelo poder de compra do consumidor e distingue a frequiência ou fluxo de diferentes bens, tentando observar o mecanismo de mercado que atenderá às necessidadss agre. gadas dos consumidores.

Alguns exemplos servirão para ilustrar melhor a idéia de como é utilizada a medição relativa. Cigarros, pão e fósfo. ros têm, por exemplo, alta frequiência de substituição em têrmos de medida relativa. Algumas pessoas consomem mais pão do que outras, mas a frequiência média do consumo de pão, numa determinada área, estabelece a frequiência de substituıção para o pão. Comparado a um piano de cauda, o pão tem alta frequiência de substituição. Entre o piano de cauda, com baixa freqüência de substituição, e o pão, com alta frequiência de substituição, situam-se, por exemplo, as camisas e meias para homens. Podemos, portanto, observar fluxos rápidos, vagarosos e moderados de diferentes espécies de bens, cada um com sua frequiência característica de distribuição.

B. Margem Bruta : - é a diferença, em dinheiro, entre o custo e o preço de venda final. Referimo-nos, aqui, à soma de tôdas as margens brutas incorridas na movimentação dos produtos desde a fábrica até o consumidor final, isto é, à soma total de dinheiro necessário para transportar um bem do ponto de origem ao consumidor final. A margem bruta pode ser também definida como o preço que um produto deve "pagar" para chegar a seu destino. Se o montante de 'margem bruta é menor do que êste preço, o produto não atińgirá seu destino.

O cálculo da margem bruta é orientado pelo mercado e baseado, na análise final, no montante de dinheiro que um consumidor despenderá por um determinado produto. Se o consumidor decidir pagar uma quantia que seja menor do que a soma dos custos de produção e de mercadização, o produto não será mercadizado, pois a margem bruta é muito baixa em relação às demais características. 
A esta altura, deveríamos responder à seguinte pergunta : está a frequiência de substituição relacionada com a margem bruta? A relação entre ambas - a qual, sem dúvida, é a que mais importa demonstrar nesta teoria - é inversa. Assim, quando a taxa de substituição é alta, a margem bruta é baixa e, inversamente, quando a primeira é baixa, a margem bruta é alta. Destarte, quando os bens se movem com alta velocidade, há um decréscimo no preço de transportá-los, não só em têrmos de custos totais, como também em função dos custos unitários.

A margem bruta na venda de um piano de cauda, por exemplo, deve cobrir o custo de vendas diretas, inclusive salários e comissões dos vendedores. Quando são vendidas grandes quantidades de um aparelho doméstico qualquer, os custos de estocagem do produto que, em geral, aparecem são custos adicionais que devem ser cobertos pela margem bruta. Podemos também observar que bens de alto valor, tais como jóias e prataria, refletem a mesma relação. Por outro lado, esta relação inversa atinge o ponto de equilíbrio quando se trata de produtos com frequiência média de substituição.

C. Adaptação : - é o trabalho aplicado ao produto a fim de que êste atenda às necessidades do consumidor. $\mathrm{O}$ serviço pode ser acrescentado ao produto durante a sua produção, em qualquer ponto intermediário de sua distribuição, ou no ponto de venda final. A adaptação é característica de todos os bens e reflete a procura meticulosa que deve ser atendida em cada mercado.

Cada adaptação representa, necessàriamente, um custo adicional que deve ser coberto pela margem bruta. Assim, as adaptaçōes feitas durante a produção tornam-se custos de fabricação que sòmente de leve afetam a operação de mercadização e, portanto, resultam em uma pequena quantia na via de distribuição. Ademais, produtos com alta frequiência de substituição têm baixa adaptação, sendo o inverso verdadeiro quando os bens têm baixa freqüência de substituição. 
Bens com frequiência média de substituição apresentam montante médio de adaptação. Demonstra-se, portanto, a relação inversa entre frequiência de substituição e adaptação, bem como a relação direta entre margem bruta e adaptação.

D. Tempo de Consumo : - é o tempo durante o qual o produto esgota sua utilidade. Esta característica está bastante relacionada à de frequiência de substituição, uma vez que os produtos com baixo tempo de consumo provàvelmente têm alta frequiência de substituição. O inverso é verdadeiro, mas deve-se observar que baixo tempo de consumo não significa, necessàriamente, que $\mathrm{o}$ mesmo consumidor repita a compra. A aspirina, por exemplo, tem sua utilidade esgotada no curto período de tempo em que está sendo consumida, mas uma nova compra de aspirina pode não ocorrer até que surja outra dor de cabeça. A idéia de tempo de consumo está mais intimamente associada a bens duráveis e não duráveis, tanto de consumo industrial como final.

Esta característica é comum a todos os bens e o montante de tempo de consumo é relativamente mensurável. O baixo tempo de consumo está diretamente relacionado à adaptação e à margem bruta e inversamente à frequiência de substituição.

E. Tempo de Procura : - é a média de tempo e distância da loja, isto é, a facilidade que é proporcionada ao consumidor pelo mercado. Suponhamos que um consumidor tenha necessidade de compra de um maço de cigarros. O esfôrço expendido por êle na procura dos cigarros é correlato ao tempo de procura. Neste caso, a dificuldade de encontrar o produto é muito baixa, pois o mercado já reagiu ao fato de que há uma procura muito grande e insistente de cigarros. A fim de atender a esta procura, são estabelecidos pontos de compra onde quer que se encontre um grande número de consumidores em potencial. O resultado dessa ação do mercado é que os cigarros podem ser comprados em muitos lugares e instituições e que o tempo de procura é baixo. Esta é uma variante da velha idéia de que os consumidores são 
motivados pela necessidade de conveniência. A partir destas relações, cada produto passou a ter uma "amplitude de conveniência". Quer isto dizer que os consumidores não podem ser forçados a despender um montante de tempo e energia que esteja em desproporção com a satisfação que esperam receber do produto que compram.

E lógico que, para certos produtos, o tempo de procura será baixo, ao passo que para outros será muito maior. O tempo e energia gastos por um consumidor para mobiliar uma nova casa, por exemplo, serão muito grandes. Portanto, o tempo de procura será igualmente grande, pois haverá necessidade de examinar as ofertas de muitas lojas e, ainda que estas não se localizem muito longe umas das outras, estarão, quase certamente, longe da casa do consumidor. O tempo de procura pode ser ràpidamente deduzido a partir do fato de que há muito maior número de lugares onde se vendem cigarros do que mobília.

O tempo de procura está diretamente relacionado à margem bruta, à adaptação e ao tempo de consumo e inversamente relacionada à frequiência de substituição. E uma característica que se pode encontrar em todos os bens e que, para cada um, pode ser relativamente mensurável.

Estas informações podem ser agora colocadas numa tabela (n. ${ }^{\circ}$ 1) que mostrará as relações das características dos bens. Mostrará, ainda, que os produtos que têm iguais quantidades relativas destas características caem dentro da mesma categoria geral.

\section{A Classificação em Côres}

A fim de facilitar a comunicação de idéias a respeito dos produtos e dos vários modos pelos quais podem ser distribuídos introduzimos, na tabela 1 , um nôvo elemento da teoria de características dos bens : a classificação em côres. A idéia de que produtos com características semelhantes são semelhantes nos leva a estabelecer três classes gerais de produtos. Escolhemos três côres para representar os conjuntos de bens: vermelho, alaranjado e amarelo. 
TABELA I

TEORIA DAS CARACTERISTICAS DOS BENS

\begin{tabular}{|c|c|c|c|}
\hline \multirow[b]{2}{*}{ CARACTERISTICAS } & \multicolumn{3}{|c|}{ CLASSIFICAÇÃO EM CôRES } \\
\hline & $\begin{array}{l}\text { PRODUTOS } \\
\text { VERMELHOS }\end{array}$ & $\begin{array}{c}\text { PRODUTOS } \\
\text { ALARANJADOS }\end{array}$ & $\begin{array}{l}\text { PRODUTOS } \\
\text { AMARELOS }\end{array}$ \\
\hline $\begin{array}{l}\text { Freqüência de Subs- } \\
\text { tituição }\end{array}$ & Alta & Média & Baixa \\
\hline Margem Bruta & Baixa & Média & Alta \\
\hline Adaptação & Baixa & Média & Alta \\
\hline Tempo de Consumo & Baixo & Médio & Alto \\
\hline Tempo de Procura & Baixo & Médio & Alto \\
\hline
\end{tabular}

Como se pode verificar na Tabela 1 , a soma das características de cada produto é diferente e a soma das características dos produtos vermelhos é menor do que a dos amarelos : a tabela mostra que os produtos vermelhos têm quatro itens de valor baixo e um de valor alto, ao passo que os amarelos têm quatro altos e um baixo.

Parece-nos útil salientar o contraste entre freqüência de substituição e as demais características mercadológicas, pois estas tendem a decrescer à medida que a freqüência de substituição aumenta. Isto equivale a dizer que, à medida que aumenta a procura de um bem, surge a tendência de se desenvolverem métodos de mercadização que representam economia nos vários aspectos dos custos de promoção e distribuição. Por outro lado, se utilizarmos o inverso da freqüência de substituição - se a freqüência de substituição representar o número médio de compras num ano, a medida inversa será o número médio de dias entre as compras verificaremos que esta medida será de valor baixo para os produtos vermelhos e alto para os amarelos, como nas demais características.

\section{A Teoria dos Sistemas Paralelos}

Antes de esquematizarmos gràficamente os produtos de acôrdo com sua classificação em côres, necessário se torna que explanemos a teoria dos sistemas paralelos de distribuição 
e promoção, pois ela nos fornece alguns conceitos que usaremos naquele esquema. Esta teoria começa com uma tese simples que pode ser exposta da seguinte maneira : as características dos produtos indicam a forma de distribuí-los e a maneira de promovê-los deve ser paralela à sua distribuição física. Assim, temos sistemas paralelos, um para distribuição física, outra para promoção.

A fim de facilitar a compreensão da discussão dos sistemas paralelos, julgamos conveniente introduzir aqui a explicação de alguns têrmos que utilizaremos adiante. Assim, lembramos que as vias de distribuição de produtos podem ser curtas ou longas. A via mais curta, naturalmente, é aquela em que o produtor entrega o bem diretamente ao consumidor final. Uma via longa é aquela em que o produto passa por diversas etapas de localização e propriedade, como, por exemplo, do fabricante para o depósito de um atacadista, dêste a uma casa varejista e dali para o consumidor.

Ademais, êste conceito de paralelismo na promoção pode ser comparado à situação de contraste que existe nas comunicaçōes: por um lado, há um circuito fechado através do qual duas pessoas podem manter uma conversação entre si; por outro, há a comunicação irradiada, como, por exemplo, a do rádio e do jornal, em que a mesma mensagem pode ser transmitida simultâneamente a muitas pessoas.

Em geral, acham-se juntas, na mercadização, vias longas e promoção irradiada, bem como vias curtas e circuito fechado ou promoção direta. A teoria dos sistemas paralelos tenta mostrar de que forma estas relações surgem naturalmente das características mercadológicas dos bens.

Como já dissemos anteriormente, os produtos podem ser classificados, de acôrdo com suas características mercadológicas, em vermelhos, alaranjados e amarelos. Os sistemas de mercadização podem ser classificados de forma semelhante. Assim, podemos dizer que os bens vermelhos exigem vias longas e promoção irradiada. Os produtos amarelos exigem vias curtas e promoção direta ou em circuitó fechado. Os produ- 
tos alaranjados são intermediários em relação às suas características mercadológicas e, portanto, são intermediários quanto à espécie de sistemas de promoção e distribuição que requerem. Há, assim, uma gradação contínua do vermelho ao amarelo e da irradiação aos métodos diretos de mercadização.

\section{Sistemas Paralelos e Características dos Bens}

Os produtos vermelhos têm alta freqüência de substituição. A transação mercadológica que ocorre com alta freqüência dá azo a que surjam a padronização e a especialização de funções. Há oportunidade para o aparecimento de emprêsas especializadas, que, por participarem da transação, dão como resultado o estabelecimento de vias longas de distribuição é relativamente custoso e uma grande percentagem de dronizadas quanto o produto em si. Este tipo de informação e persuasão não precisa seguir a via longa de distribuição e é, então, irradiado aos consumidores através dos meios eletrônicos e da imprensa.

Os produtos amarelos têm baixa frequiência de substituição e altas as demais características, como, por exemplo, a adaptação. As exigências para êste tipo de produto tendem a variar de consumidor a consumidor. A adaptação envolve uma variedade de meios através dos quais os bens são ajustados às exigências individuais. $\mathrm{O}$ processo de mercadização é relativamente custoso e uma grande percentagem de margem bruta acompanha, necessàriamente, a alta adaptação. A oportunidade de padronização e especialização é baixa em relação aos produtos vermelhos. O movimento físico e a promoção são estreitamente associados e a comunicação direta em relação ao que está disponível e ao que é necessário dá como resultado a entrega do produto "sob medida". A relação entre um freguês e seu alfaiate ilustra êste tipo de mercadização. Muitos tipos de equipamento industrial são desenhados especialmente para um determinado freguês e estariam, também, na extremidade da parte amarela da escala. A via curta prevalece nestas situações e tôda a promoção e a 
comunicação a ela relativa se desenvolvem através de um circuito fechado.

Muitos produtos se acham na faixa intermediária a que chamamos de alaranjada. Neste caso, há especificações padronizadas para os bens, mas também conhecimento de que os mesmos terão que ser adaptados, em maior ou menor grau, às necessidades individuais. A freqüência de substituição é suficientemente alta para haver oportunidade de padronização e especialização. Pode haver, pelo menos, um intermediário, como, por exemplo, um concessionário que compre o carro do fabricante e o venda ao consumidor. Os meios de irradiação são usados na promoção, mas não na escala em que se aplicam aos produtos vermelhos, tais como sabonetes e cigarros. O distribuidor industrial é, freqüentemente, coadjuvado em seus esforços por vendedores especializados empregados pelo fabricante. É provável o uso de propaganda de caráter de semi-irradiação. Isto significa que as mensagens são preparadas especialmente para vários segmentos do mercado nos quais o apêlo deve ser diferente. Êste método se coloca entre a mensagem padronizada para todos os consumidores e a negociação de circuito fechado.

A esta altura devemos fazer uma observação que servirá para qualificar o que acima dissemos : os sistemas de mercadização não são tão flexíveis quanto nossa discussão indica, mas devem aderir a um ou outro tipo. Assim, uma via de distribuição física poderia ter duas ou três etapas, nunca duas e meia. Entretanto, a idéia de variação contínua ao longo de uma escala é válida, de forma geral, por causa das combinações que propicia. Um fabricante pode vender parte de sua produção através de atacadistas que vendam a varejistas e o restante diretamente a varejistas. As proporções podem variar no tempo, de forma que uma determinada via pode tornar-se dominante num certo momento. Ademais, uma promoção irradiada pode assumir gradualmente maior importância, se bem que um montante alto mas em declínio de adaptação esteja sendo usado em algumas vendas individuais. A Tabela 2 demonstra a relação entre os produtos e seus respectivos sistemas de mercadização. 


\section{TABELA 2}

\section{RELAÇÃO ENTRE PRODUTOS E SISTEMAS DE MERCADIZAÇ̃̃O}

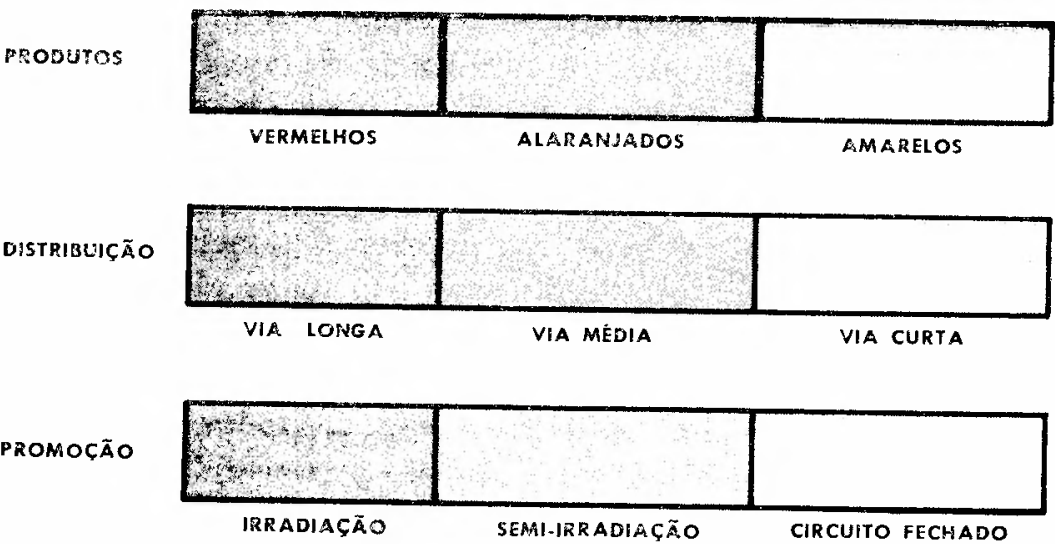

\section{Promoção Irradiada e Direta}

Resta-nos ainda dar outra definição dos dois tipos de promoção. O meio promocional é do tipo de irradiação quando a promoção é feita sem conhecimento prévio da identidade dos consumidores em potencial. A firma que emprega êste tipo de promoção confia na probabilidade de contato com os consumidores em potencial do produto ou serviço. O meio de distribuição para êsse produto é tal que o freguês que foi alcançado por êste tipo de promoção pode fazer sua escolha de forma conveniente e rápida. O consumidor poderá encontrar, a curta distância, lojas que vendam o produto promovido. Assim, o intervalo de venda, em relação ao tempo e à distância, é encurtado e a eficiência do meio de promoção por irradiação é aumentada. O fato que torna econômico êste tipo de mercadização é que, se bem que os consumidores em potencial não sejam identificados, éles representam uma proporçäo bastante grande do público em geral que estará exposto à mensagem irradiada. 
G R A F I C O 1

\section{AGRUPAMENTO ESQUEMÁTICO DE ALGUNS PRODUTOS}

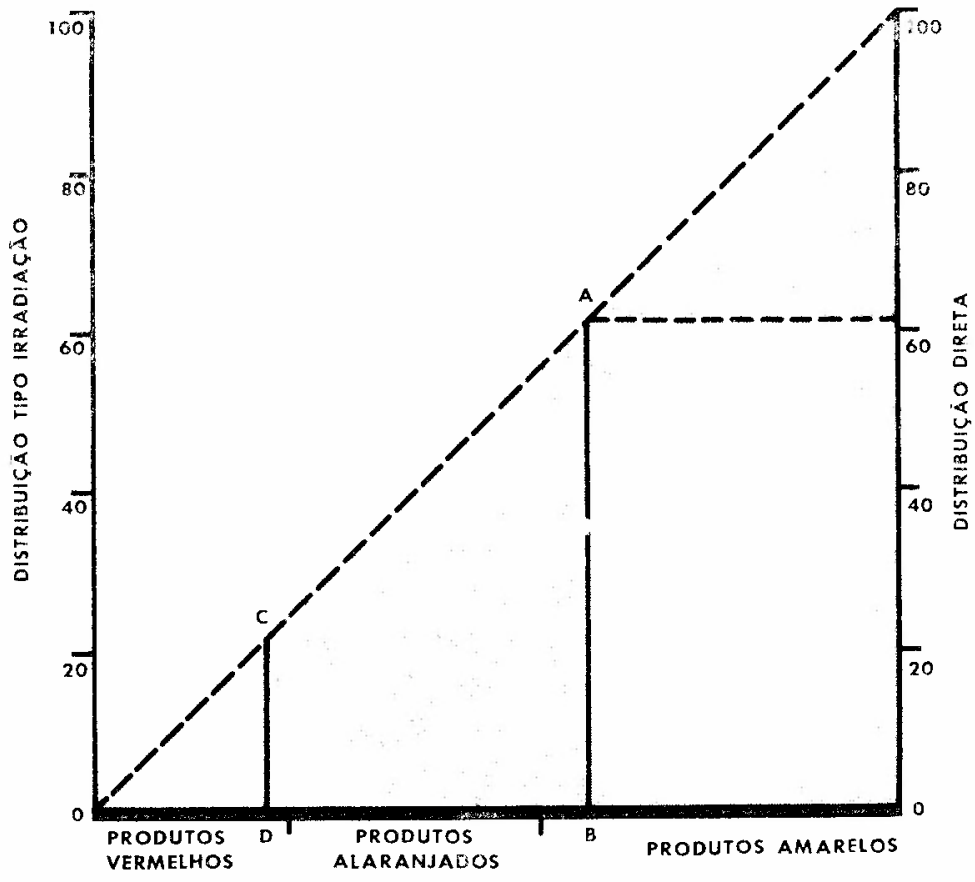

Em oposição à promoção irradiada há a direta. A definição dêste segundo tipo de promoção indica que o recipiente da comunicação direta é conhecido prèviamente, de forma que a mensagem chega ao freguês com seu nome e enderêço, ou através de uma determinação prévia de sua necessidade e capacidade de comprar o produto. O meio mais direto seria um vendedor que procura um freguês em potencial cujo nome e enderêço conhece c do qual a necessidade e capacidade de comprar já foram avaliadas. Outro meio direto seria uma carta ou telegrama ao consumidor potencial. Outro, ainda, seria a venda de porta em porta ou a remessa de cartas a pessoas arroladas em listas diversas. Esstes meios de promoção direta mostram que pode haver um intervalo de vendas maior ou menor entre o freguês e o produto. 
E evidente que a promoção por irradiação cria um maior intervalo de vendas. Assim, também, é evidente que o raio no qual o freguês deve procurar pelo produto é aumentado. A compensação por êste raio aumentado está nos meios mais intensos de promoção que resultam da promoção direta, pois êstes induzirão o consumidor a sofrer maiores inconveniências quanto a tempo e distância a fim de obter o produto.

Estas definições fazem-nos voltar diretamente à teoria das características dos bens. Sempre que haja necessidade de substituição freqüente, torna-se fisicamente impossível efetuar a distribuição por meios diretos. Tal situação exige venda e movimento em massa de produtos, pois só assim tôdas as economias trazidas pelo volume de vendas e de transporte podem ser aproveitadas. A baixa margem bruta na transação individual exige que seja ampla a margem bruta agregada resultante da venda em massa. Seria ridículo, por exemplo, adaptar cigarros às necessidades de cada consumidor no ponto de venda, pois a margem bruta que se tornaria necessária para fazer tal trabalho levaria os cigarros à classe de preços da prataria e o número de pessoas que poderiam comprá-los em tal base seria muito pequeno. Montar um diamante numa cravação especial, entretanto, não é ridículo, pois a margem bruta disponível é suficientemente alta para justificar essa adaptação.

\section{Representação Gráfica de Produtos}

Podemos agora esquematizar as gradações de produtos, desde o vermelho até o amarelo. Assim, apresentamos, no gráfico 1, duas coordenadas com uma escala percentual simples de 0 a 100. Se bem que o valor ponderado de qualquer produto pudesse ser representado numa única linha, achamos vantajoso usar um gráfico bidimensional com o propósito de tornar possível a observação de conjuntos de produtos. A escala de valores, dessa forma, consiste de todos os pontos da linha diagonal do gráfico em questão.

Uma vez que há um número infinito de pontos em qualquer segmento de linha, a escala fornece grupos infinitos de produtos. Se o gráfico fôsse suficientemente grande, poderíamos de 
senhar uma linha vertical para cada produto existente no mercado. Entretanto, mesmo depois que desenhássemos essas linhas haveria, ainda, um número infinito de posições entre elas. Muitas dessas posições serviriam para identificar bens que foram retirados do mercado ou que poderão nêle ser introduzidos futuramente.

A linha $\mathrm{AB}$ representa um produto que tem um valor de ordenada de 63 que indica a soma das características dêsse produto. $\mathrm{Na}$ classificação geral, êsse produto tem $63 \%$ de características amarelas e $37 \%$ de vermelhas. Isto traduzido em têrmos de mercadização significa que o produto pode ser, por exemplo, vestidos para senhoras vendidos através de lojas de departamentos e enviados diretamente da fábrica a estas lojas, nas cidades grandes. As cidades pequenas são servidas por atacadistas que têm estoques dêste produto ao lado de outros. Assim, a via utilizada na distribuição dêste produto seria direta para lojas grandes de departamentos e de semi-irradiação para atacadistas em cidades pequenas.

A linha CD tem um valor de características amarelas de 15 e de vermelhas de 85 , o que coloca êste produto na classificação geral como vermelho. A soma do valor das características, na escala de 0 a 100 , dá $85 \%$ de características vermelhas. Êste produto pode ser um sabonete que é vendido principalmente por meio de distribuição irradiada, através de atacadistas ou varejistas. Os $15 \%$ de características amarelas podem indicar as atividades de vendedores especializados que fazem vendas diretas da fábrica ao varejista, resultando num tipo mais direto de distribuição.

A posição de um produto nessa escala de côres não é estática. A maioria dos produtos, ao ser introduzida no mercado, se encontra na classificação amarela. A medida que os bens se tornam mais conhecidos e satisfazem um segmento maior da procura, sua frequiência de substituição aumenta e o produto se desloca em direção à extremidade vermelha da escala.

Contudo, existe também uma tendência oposta, na mercadologia, que resulta da constante redução da margem bruta, à medida que o bem se desloca para a extremidade vermelha da es- 
cala. As instituiços mercadologicas, no estorco de manter sua margem bruta, podem melhorar ou diferenciar um pioduto que se deslocou para a categoria vermelha, a fion de faze? com que estas novas variedades voltem a ana amarela. Nessce ponto, a comperiçăo por volume scrve para novamente arelerar a movimento do produto on direcon a extremidade ver melha da escala.

Demonstraças Grafica dos Sistemas Paratelos

O Gráfico 2 demonstra de que forma a teoria dos sistemas paralelos pode ser utilizada na prática.

\section{G R A F I C $\quad O^{\prime} \quad 2$}

\section{APLICAÇÃO DOS SISTEMAS PARALELOS}

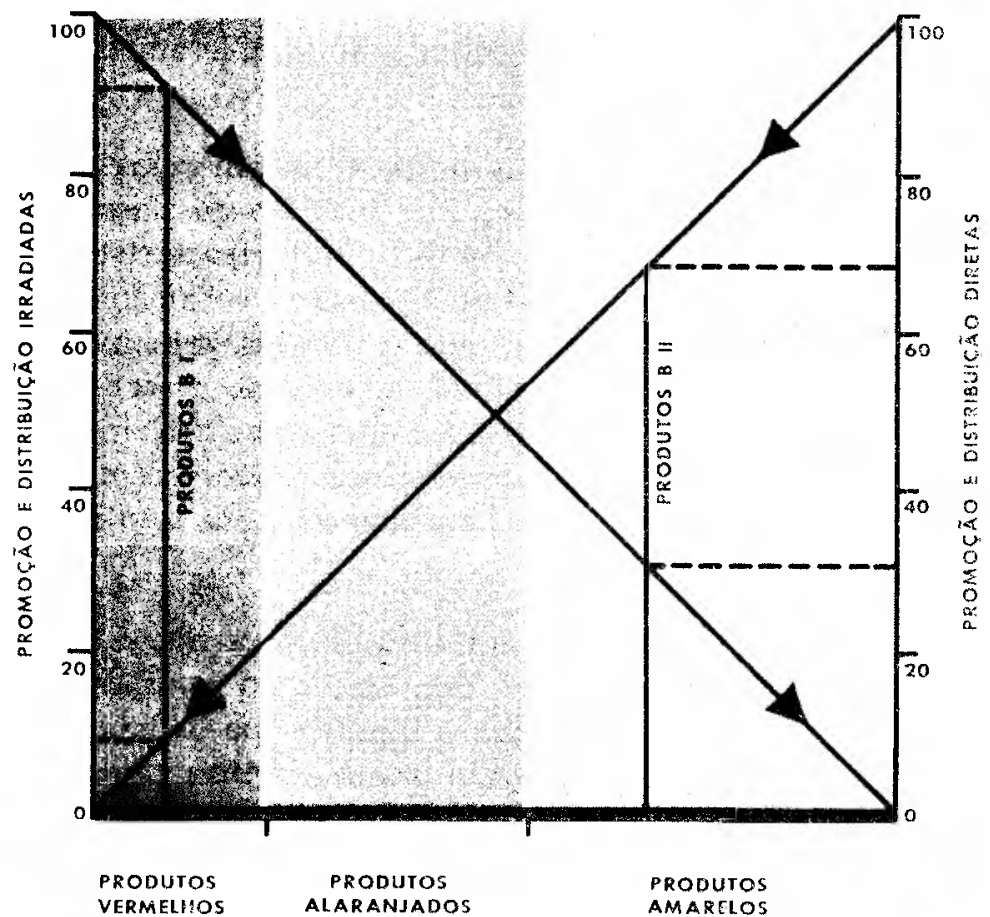

Note-se que o segmento da linha é maior para os produtos alaranjados do que para os vermelhos e maior para os amarelos 
do que para os alaranjados. É evidente que o número de itens distintos de qualquer estoque de produtos aumenta à medida que a frequiência de substituição diminui. Uma farmácia por exemplo, deve vender maior número de itens distintos do que uma mercearia para atingir o mesmo volume de vendas. Uma loja de vestidos caros para senhoras deve apresentar maior variação em estilos e modelos do que uma loja que trabalhe com vestidos baratos. Produtos vermelhos são aquêles que, por sua própria natureza, atendem a necessidades de vários mementos e, portanto, são comprados com frequiência, ao passo que nos produtos amarelos deve haver maior número de itens de venda menos frequiente para a satisfação de situações diver. sas e diferenciadas de uso.

O Gráfico 2 não tenta mostrar uma relação matemática precisa, uma vez que os dados em que se baseia não são matemàticamente precisos, mas auxiliar a compreensão dos problemas que devem ser resolvidos pelos administradores de emprêsas. O raciocínio é dedutivo, do geral para o específico, fornecendo uma base para respostas que pode ser adaptada a cada caso em particular. O diagrama apresenta percentagens complementares que devem ser tomadas como medidas aproximadas dos tipos e montantes de distribuição e promoção. A distribuição por via longa e a promoção por irradiação são agrupadas como elementos correlatos no composto mercadológico e chamadas de "irradiadas" para simplificação. A linha que representa êstes dois elementos em combinação inclina-se para a direita. pois êste tipo de despesa será relativamente alto para os produtos vermelhos e relativamente baixo para os amarelos. Da mesma forma, a distribuição por via curta e a comunicação em circuito fechado são agrupadas sob a designação de "diretas". A linha que representa a distribuição e promoção diretas sobe da esquerda para a direita.

\section{Aplicação das Teorias a um Problema Real}

Há algum tempo atrás, um fabricante de produtos que variam do vermelho ao amarelo, na escala, raciocinando com as duas teorias aqui expostas foi capaz de localizar a posição de um certo produto na linha-base. Êle traçou, então, a ordenada 
que representava êste produto e concluiu pelo diagrama que a distribuição adequada seria direta e, da mesma forma, que a promoção direta deveria ser utilizada. Ao rever o que estava realmente sendo feito com o produto, êle verificou que a promoção era predominantemente irradiada e a distribuição direta. Assim, a promoção e a distribuição não eram paralelas, o que explicava o desempenho fraco do produto.

A pesquisa havia confirmado que êste era um excelente produto e que seu preço havia sido corretamente determinado, de forma que se poderia esperar um razoável volume de vendas. As vendas planejadas para o produto não tinham sido atingidas e, assim, para corrigir a situação, um programa mais extenso de promoção irradiada foi iniciado. Com êste programa, entretanto, quase nenhum aumento se verificou nas vendas. Neste ponto, o fabricante decidiu seguir o plano de distribuição e promoção indicado pela análise da teoria dos sistemas paralelos. Foi iniciado um programa de promoção direta que imediatamente trouxe resultados. As estimativas de vendas foram realizadas e o fabricante decidiu estabelecer um departamento especial para o produto que, desde aquêle tempo, tem conseguido ainda maiores vendas com custos menores do que os estimados.

Uma análise mais detida dêste caso revelou que a promoção irradiada estava atingindo milhares de pessoas que não estavam qualificadas a usar o produto e que o tipo de mensagem era tal que os consumidores em potencial não estavam capacitados a especificar o produto mesmo que desejassem fazê-lo. Um estudo cuidadoso do problema mostrou que a promoção direta produziu todos os resultados de vendas desejados. Assim, o custo da promoção irradiada devia ser pago pelos consumidores qualificados e o resultado dava um preço mais alto do que o necessário. O resultado final desta operação foi que os preços foram reduzidos e a posição de lucro do fabricante e das emprêsas que distribuíam o produto foi melhorada.

O Produto $\mathrm{B}_{2}$, no Gráfico 2, representa o produto discutido acima em sua posição correta. Fazendo-se a leitura do valor da ordenada na escala vertical verifica-se que o produto que ela representa deveria ter uma distribuição $69 \%$ direta e uma 
promoção também $69 \%$ direta. A leitura dos $31 \%$ complementares indica que $31 \%$ da distribuição deveriam ser irradiados e que $31 \%$ da promoção deveriam ser também por irradiação.

O Produto $B_{1}$, no Gráfico 2, representa o produto $B_{2}$ localizado incorretamente. Esta localização foi baseada numa avaliação do método de promoção que estava sendo utilizado. $\mathrm{Na}$ verdade, êste produto estava sendo distribuído corretamente por um método direto e, consequientemente, os consumidores que poderiam ter sido influenciados a usá-lo não tinham meios para satisfazer seu desejo; o produto não estava disponível no varejo de forma que o consumidor pudesse adquiri-lo quando dêle necessitasse.

\section{Conclusões}

Ao fazer-se a análise do produto e de seus programas de distribuição e promoção, verificar-se-á que muitos produtos não estão em conformidade com a teoria dos sistemas paralelos e, entretanto, parecem ser de sucesso. Isto não deveria, entretanto, desmentir a teoria. Tais resultados podem indicar que melhores resultados poderiam ser obtidos se os programas fôssem modificados na direção indicada pela teoria. Isto pode ser feito, muitas vêzes, com um pequeno custo, pelo uso de áreas de vendas como teste. Assim, a adaptação pode ser feita sem afetar o sistema em que o produto está operando. Os resultados de tal experiência deveriam confirmar a análise propiciada pela teoria dos sistemas paralelos.

As duas teorias são excelentes instrumentos de mercadologia e auxiliam, substancialmente, a compreensão dos processos de mercadização e de suas interações. Ao mesmo tempo, elas podem tornar-se ineficientes nas mãos daqueles que não forem peritos em mercadologia. Por outro lado, mesmo os que o são devem estar sempre atentos aos avanços tecnológicos e à forma pela qual afetam os processos de mercadização. Ademais, a perícia na utilização dêstes instrumentos deverá aumentar com a experiência advinda de sua aplicação a situações reais de mercadização. 